BÉATRICE PICON-VALLIN

Pesquisadora do Centre National de Recherche Scientifique (CNRS), Laboratório ARIAS, França. Professora do CNSAD (Conservatoire National Supérieur d'Art Dramatique) de Paris.

Tradução MARTA ISAACSSON²

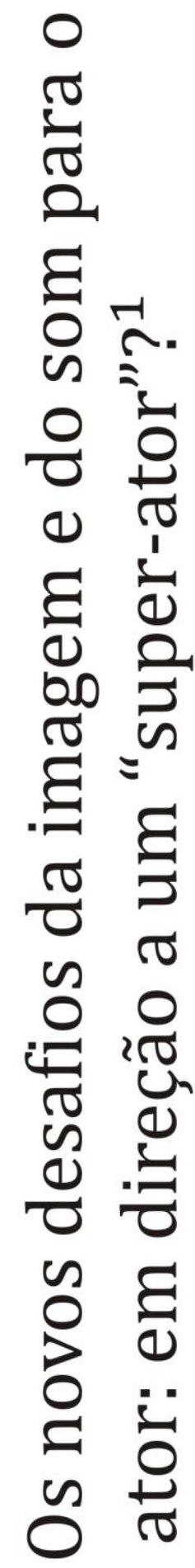


Há muito tempo, o teatro se interessa pela confrontação carnal dos corpos e de seu duplo, impalpável alquimia de sombra e de luz. E, no interior de práticas interdisciplinares, que fazem parte da história da cena do século XX, em que a porosidade das fronteires entre as artes do espetáculo foi um dos fatores determinantes, a imagem - ontem química, hoje digital - tomou cada vez mais lugar de destaque. Ilustrativa ou atriz, ela atribui ao corpo do ator diferentes modalidades de presença, oferece a ele "fantasmas" como parceiros, dota-o de um corpo "aumentado" ou adapta-o ao olhar "gráfico" do público. Ela faz penetrar o espectador em seu corpo, ou atomiza esse em "grandes planos" explodidos. Magia espantosa: corpos midiatizados e corpos vivos podem se entrelaçar... As imagens colocam o ator polivalente diante de desafios a destacar. As tecnologias da imagem e do som sublinham a necessidade de uma formação sólida, de um aprendizado eficaz, porque desestabilizam as relações entre os parceiros de equipe e de criação, inauguram modos diferentes de trabalho, em que o processo, $o$ work in progress, torna-se objeto de todas as atenções. Elas fazem da cena um lugar experimental e crítico para pensar, de forma similar, as mutações da sociedade.

\section{Os modelos históricos}

Começaremos evocando o radicalismo de Vsevolod Meyerhold, encenador e pesquisador, cujo teatro permanece, para aqueles que pertencem já ao século XXI, um lugar de audácia, de virtuosidade e de experimentação de onde emana, como escreveu Peter Sellars e Elizabeth LeCompte, do Wooster Group, "um apelo doloroso que nos convida a continuar o combate sem nos deixar em paz"3. Ora, segundo Meyerhold, encenador por excelência, o ator é o centro do teatro: "Mesmo se retirarmos a palavra, o figurino, a ribalta, as coxias, o edifício teatral, enquanto continuar o ator no domínio pleno de seus movimentos, o teatro permanecerá o teatro", escreve ele antes de $1914^{4}$. É o movimento que constitui o meio de expressão essencial deste ator, "rei" do teatro. Nos anos trinta, a atuação do ator constitui uma das duas partes da definição de encenação que Meyerhold dá, a "composição de conjunto" constituindo a segunda. Ele afirma então:

\footnotetext{
Não há nenhum encenador, se falamos de um autêntico encenador, que coloque sua arte acima dos interesses do ator, figura principal do teatro. O domínio da encenação, a arte da construção dos jogos de cena, a alternância da luz, da música, tudo isso deve servir a atores magníficos, altamente qualificados.
}

Meyerhold considera ainda o ator como um "compositor" (textual, visual, sonoro) de sua própria atuação. Segundo ele, a encenação tem também lugar no seio da arte do ator e, em sua obra complexa de encenador, eleva o ator ao status de criador completo, impondo a esse, 
exigências particulares. Criticando o "ator-acomodado", ator gramofone, armário falante, Meyerhold retorna à apologia do ator polivalente, entendido como um verdadeiro músico, bailarino, artista de circo e de variedades, capaz, em qualquer momento, de reforçar sua atuação ou de romper sua continuidade na exploração (performance) da música ou da dança. Faz do ator o lugar de síntese das artes, de todas as artes que seu palco acolhe - artes plásticas, música, dança, circo, music-hall. Para esse ator, pensa uma formação completa que promova o desenvolvimento de sua precisão e de sua presença cênica, tornando-o capaz de inventar um jogo não psicológico, suscetível de fomentar as emoções do espectador ${ }^{5}$.

Tudo é permitido para atingir este objetivo, pois, diz Meyerhold, “em arte, não há técnicas proibidas; somente existem técnicas mal utilizadas" ${ }^{\text {. E }}$, após ter indicado, em um primeiro momento, o modelo do funâmbulo, do bufão, ele orienta seus atores em direção aos burlescos americanos. Longe de procurar destruir o teatro, ele, ao contrário, alarga seus limites, explorando seu território, cujas fronteiras são móveis. Dessa forma, vai inclusive introduzir telões e projeções de imagens e textos sobre o palco e sonhando, desde 1923, às projeções de filmes, o que só viria a realizar em 1927.

No lugar da "super-marionete" idealizada por Craig, e que, aliás, ele evoca por várias vezes, é mais o conceito de "super-ator" que Meyerhold defenderia - "super-ator", ou seja, concretamente aquele que conheceria as grandes tradições teatrais e as revisitaria, aquele que "comporia" sua atuação após ter decomposto seu material de trabalho, encenador dele mesmo, aquele que não temeria que as imagens fossem introduzidas sobre o palco porque teria consciência que a nova arte do século XX, o cinema, se desenvolve com e, ao mesmo tempo, em que o teatro de avant-garde, o seu teatro.

Mesmo reconhecendo que Piscator, fazendo igual apelo a todas as artes e a todos os domínios do saber e empregando também tecnologias mais modernas e imagens sobre a cena, vai mais longe do que ele na utilização desses recursos, Meyerhold considera que o encenador alemão está, porém, sobre um caminho perigoso, pois negligencia o ator, não se interroga sobre sua formação, nem em geral, nem em particular, para uma cena assim transformada. Assim, diz ele em uma entrevista 1928, em Paris:

Eu não vi em Berlin o teatro de Erwin Piscator, diz ele, em uma entrevista. "Isso teria me interessado, ainda que Piscator esteja, a meu ver, sobre uma via equivocada. Eu vi as fotografias de seus cenários, a planta de seu teatro. Eu conheço o tema de suas peças. Ele não compreendeu o problema que se colocou para ele. Em seis meses, Piscator acreditou poder criar em Berlim um teatro revolucionário. Para isso, construiu uma cena moderna e voltou toda sua atenção para o aperfeiçoamento material da técnica teatral. É unilateral. O problema que se coloca ao encenador tem múltiplos aspectos. A cena, o teatro, são quadros. É preciso colocar em proporção neste ambiente os gestos, a voz do 


\section{OS NOVOS DESAFIOS DA IMAGEM E DO SOM PARA O ATOR: EM DIREÇÃO A UM "SUPER-ATOR"?}

BÉATRICE PICON-VALLIN

ator. É isso que Piscator não procurou. Ele construiu uma nova sala, mas ali ele faz atuar velhos atores"

Se Meyerhold não pôde ir mais longe tal como ele gostaria na utilização das tecnologias contemporâneas (ele sonha, às vezes, com a América para dispor dos meios técnicos que deseja), as plantas do teatro por ele concebido, a partir do final dos anos vinte, revelam a previsão de múltiplas superfícies de projeção nas paredes e no teto, remetendo, por vezes, às plantas de Gropius e de Piscator, a alguns dispositivos de Jacques Polieri e, mesmo mais perto de nós, ao espaço de ensaio e de apresentação La Caserne, construída por Robert Lepage, no Canadá. Ele tentou ainda responder à questão da formação de um ator que, pertencendo a um mundo em mutação, tanto do ponto de vista político quanto científico, poderia atuar sobre uma cena capaz de deixar penetrar a atualidade do mundo e o curso da história, na forma de um espetáculo-reunião (Ao Amanhecer), ou por meio de telas (A Terra Erguida). Quando Piscator afirma que a técnica é "uma necessidade artística do teatro moderno", "adotando os mesmos caminhos que eles" - não pressupõe a técnica como um fim em si, afirmando que essa não deve ser utilizada para seus efeitos, mas destinada a romper a antiga forma da caixa óptica, a "alçar [a cena] ao plano histórico" 9 . Em seu teatro da praça Bülow, ele melhora o equipamento cênico, instalando ali aparelhos de projeção cinematográfica e outros, destinados a apresentar imagens gigantescas sobre o ciclorama da cúpula. E, no célebre projeto do "teatro total", a cena poderia ser inteiramente invadida por filme ou por projeções. Mas, se ele afirma que a técnica deve permitir ao teatro desenvolver novos conteúdos ${ }^{10}$ - fazendo entrar os conflitos contemporâneos nos limites do palco e respondendo às modificações dos ritmos temporais do público -, é somente muito mais tarde, em seu Dramatic Workshop, em Nova Iorque, que dispõe de tempo para propor aos atores aulas conjuntas com os técnicos, para formar atores (e autores) para um "jogo objetivo", considerado como um instrumento óptico, espécie de "luneta do tempo."11

\section{Desaparecer em sua especificidade ou reforçá-la? Qual o caminho para o ator?}

Uma parte da história do teatro do século XX é constituída, de um lado, pelos avanços da técnica sobre a cena, em que os criadores de vanguarda tentam alçar sua arte ao nível do real sem o imitar, e, de outro, pela recusa e recuo daqueles que consideram essa mesma técnica inimiga da tradição, destruidora das artes vivas - signo da "desesperança histórica", de que fala Bernard Stiegler ${ }^{12}$ : sintoma de uma trágica recusa da época. Anos vinte, anos sessenta, anos oitenta: as imagens-projetadas, difundidas sobre grandes e depois pequenas telas fixas ou móveis, em preto e em branco ou em cores, documentos ou ficções, imprecisas ou em alta definição - atravessaram e depois se instalaram sobre a cena. O processo se acelera ou se intensifica em decorrência de uma maior facilidade de utilização dos equipamentos de registro, difusão, projeção, assim como graças às técnicas desenvolvidas por artistas, 


\section{OS NOVOS DESAFIOS DA IMAGEM E DO SOM PARA O ATOR: EM DIREÇÃO A UM "SUPER-ATOR"?}

\section{BÉATRICE PICON-VALLIN}

engenheiros e "bricoladores" tão diferentes de Josef Svoboda e Jacque Polieri, os precursores dos anos sessenta ${ }^{13}$.

No início do século XXI, o ator é colocado diante do problema de seu anunciado desaparecimento. De um lado, os fenômenos de reality shows e de big-brothers tendem a demonstrar que qualquer um pode se tornar ator. Além disso, o ator pode ser substituído sobre a cena, às vezes, de forma mesmo vantajosa, por sua imagem filmada (atores ausentes do palco, nas coxias, distantes, ou mortos) ou por sua imagem virtual, produzida por captadores fixos sobre seu corpo - um clone? Diante desses fenômenos, cuja fraqueza do primeiro não deve ocultar a riqueza potencial do segundo (o ator terá a possibilidade de assumir sua direção, de gerá-la, sem mais se submeter ao exterior), cintila a idéia já antiga, secular. Aquela de um "super-ator" que saberia utilizar tanto seu corpo-instrumento (voz, movimento) quanto os meios técnicos da atuação tradicional, sobre os quais ele teria se tornado mestre, e as tecnologias mais modernas da imagem e do som como novos instrumentos de trabalho que, longe de se submetê-lo, podem dotá-lo de qualidades suplementares, "aumentá-lo, em sentido similar à realidade aumentada sobre a qual se fala em fotografia digital.

Cronologicamente, podem-se distinguir dois problemas diferentes. Inicialmente, o ator viu-se diante das imagens do mundo projetadas ou difundidas sobre a cena, o mundo exterior penetrando sobre o palco, ou adentrando como em Meyerhold ou Piscator. Depois, continuando eventualmente a afrontar essa desestabilização, ele viu-se confrontado às suas próprias imagens, aquelas de seu corpo manipulado - dividido, aumentado, reduzido ou fragmentado, aquelas de seu personagem, seus fantasmas, suas imagens mentais, a câmera podendo penetrar no interior de seu cérebro ou de sua intimidade física. Mais recentemente, percebeu-se que os microfones, longe de serem simples transmissores da voz, ajudam os atores a dar nuances sutis, a jogar com a proximidade, com a intimidade do sopro emitido ou com o reforço da distância.

Esses instrumentos tecnológicos, desagradáveis, ainda indiscretos e freqüentemente inestéticos, puderam ser domesticados por artistas de teatro a partir do momento em que foram miniaturizados. Etapa importante: a câmera de vídeo se torna instrumento da atuação para o ator quando ele a integra a seu processo de trabalho. Assim, Philipe Caubère ensaia diante de sua objetiva, o que lhe permite substituir o olhar do encenador que ele recusa. No Odin Teatret, os atores criam espetáculos a partir de improvisações registradas em vídeo que são retrabalhadas após o exame dos registros: a câmera obtém, então, status de caderno de anotações.

A câmera pode ser manipulada em cena por atores que, graças às imagens produzidas, aproximam seus parceiros do público, oferecendo imagens em close. Assim, os operadores de câmera de $O$ Mercador de Veneza, de Shakespeare, são considerados, no projeto de encenação de Peter Sellars, como os servidores de cena do teatro japonês porque, ao invés de iluminar o rosto dos atores com lanternas, como na tradição da Ásia, eles os filmam para 
melhor revelar seus traços aos olhos do público. É preciso que o ator saiba filmar ou que ele saiba se prestar à filmagem. Na encenação de $O$ Pavilhão de Peônias, de Tan Xian Zu, também de Peter Sellars, a heroína, interpretada pela atriz moderna, dubla a atriz tradicional, pinta seu auto-retrato, se filmando, se olhando na câmera como se fosse um espelho. Para Humilhados e Ofendidos segundo Dostö̈evski, encenado por Frank Castorf ao Volkbühne de Berlin, os atores se filmam com a câmera sobre o ombro, se espiando, se observando, desvendando sobre uma tela, através de uma espetacular figura fílmica e, em um mergulho no interior de um corredor estreito, um universo deformado e estranho, onde rostos e corpos se empilham em uma intimidade perturbadora.

$\mathrm{O}$ ator, de quem é exigido competência para se tornar um fazedor de imagens, pode, ao mesmo tempo, ser submetido às imagens projetadas pelos técnicos e imaginadas pelo encenador. Assim, as figuras das atrizes projetadas sobre uma tela imensa em Dança da Morte, de Strindberg, montada por Mattias Langhoff, revelam ao espectador os fantasmas do personagem, mas também vêm suavizar a atuação da atriz, lhe permitindo atuar sobre outros temas, além daquele evocados pelas imagens.

Após o teatro da era científica, aquele da era tecnológica?

Como representar hoje, se pergunta o jovem encenador brasileiro Francisco Moura, na primeira etapa de seu espetáculo Angelus novus, o ódio do teatro ou a barbárie positiva ${ }^{14}$ Pois se trata de um novo espaço de representação, composto por imagens e por sons produzidos por tecnologias analógicas ou digitais, aberto a múltiplas janelas para outros registros de realidades, outras temporalidades, um espaço-tempo híbrido que implica uma atuação diferente. O vídeo ao vivo sobre a cena permite, como diz William Forsythe, "dessincronizar o presente". A cena acolhe o "policrônico"," o passado e o futuro, mas também o mundo interior e aquele do além desse, dos sonhos, dos espectros. O palco se abre à natureza (os pássaros filmados que piam sobre os monitores de São Francisco de Assis, de Olivier Messiaen, encenado por Peter Sellars), ou se torna um espaço onde real e irreal coexistem. Em $O$ Pavilhão de Peônias, já citado, em que um dos amantes está vivo enquanto o outro está morto, eles

se reencontram somente em seus sonhos. A heroína adormece sobre uma cadeira e no encosto, ao lado de sua cabeça, há uma tela de televisão. A imagem do seu amante aparece, enquanto ele mesmo se encontra dançando próximo à boca de cena. Assim, o espectador vê o ator real sobre o palco e também como uma imagem sobre a tela ao fundo. ${ }^{16}$ 


\title{
OS NOVOS DESAFIOS DA IMAGEM E DO SOM PARA O ATOR: EM DIREÇÃO A UM "SUPER-ATOR"?
}

\author{
BÉATRICE PICON-VALLIN
}

A cena torna-se então uma espécie de novo território, em que as fronteiras se diluem, fronteiras entre as artes, entre as culturas, entre as temporalidades, entre o mundo dos vivos e aquele dos desaparecidos.

As telas se multiplicam, se diversificam. A cena pode estar fragmentada por telas e superfícies, determinando os espaços de projeção que tornam visível o invisível. Mas qualquer objeto pode se tornar superfície de projeção. No teatro de metamorfose de Josef Svoboda, as telas são esféricas, móveis, inclinadas. Ele projeta ali suas imagens pintadas, encaixadas, trabalhadas, sobrepostas, fazendo variar o conjunto de superfícies de projeção: malhas metálicas, cortinas feitas de cordas esfiapadas, tudo deixando ver o fundo. Hoje, se projeta sobre papel, tecidos, sacos plásticos amarrotados, sobre o corpo ou o rosto do ator, que pode também ganhar outro rosto, uma máscara de luz a qual deve saber portar "interceptar"? -, e por vezes, falar com uma outra voz, de forma que a adequação dos movimentos de seus lábios com o dispositivo sonoro lhe permita fazer aparecer (Angelus Novus)...

Nesta área de representação integral e imediatamente transformável pelo poder da luz - porque essas imagens são sempre dependentes da luz - nesse espaço de aparições múltiplas, como atuar quando o vídeo amplia, multiplica o corpo do ator em cena, quando ele o divide ou o atomiza, capturando somente uma de suas partes enquanto ele se encontra presente de corpo inteiro, preso pela cintura e pesado pela carne que se ancora no solo, enquanto seu rosto, suas mãos ou seus pés são aumentados ou suspensos no ar pelas imagens em vídeo?

Esses fenômenos de transformação pela tecnologia podem se referir unicamente à voz. Assim, Martin Wuttke, no espetáculo Artaud e Hitler no Café Romano, de Tom Pikert (Berliner Ensemble), atua em uma cela de vidro recheada de microfones de diferentes tipos. $\mathrm{O}$ ator deve não somente saber utilizar esses objetos técnicos para dar a sua voz as modulações e as intensidades previstas, mas também dominá-los, ser mais forte do que eles. Sobre o que Wuttke oferece uma formidável metáfora quando, ao final do espetáculo, após sua virtuosa atuação de "ator aumentado" pela força dos microfones sensíveis e variáveis, ele se libera da cela tecnológica, onde estava encerrado, e se coloca a cantar, triunfando sobre o dispositivo do qual, do início ao fim, ele se manteve o mestre.

Numerosos são os problemas a que se encontra confrontado o ator. Porque se a imagem pode, por vezes, o liberar, representar em seu lugar, muito freqüentemente, ela pode não lhe deixar um instante de tranqüilidade. Ele pode ser visto em todos os lugares: atuando no fundo da cena, ele sabe que o espectador o vê em grande plano sobre um monitor, ou, atuando de costas, tem consciência de ser observado de frente através de telas ou monitores. Em $O$ Idiota, espetáculo do Volksbühne montado por F. Carstof inspirado na obra de Dostoïevski, as imagens, capturadas continuamente por câmeras de segurança por dois cameramen, são tratadas ao vivo e projetadas em um grande telão e em monitores, enquanto o público, em número reduzido, é repartido e colocado em posição central em um dispositivo 


\title{
OS NOVOS DESAFIOS DA IMAGEM E DO SOM PARA O ATOR: EM DIREÇÃO A UM "SUPER-ATOR"?
}

\author{
BÉATRICE PICON-VALLIN
}

complexo, onde assiste simultaneamente ao espetáculo de teatro e ao filme da representação. Somente atores bem treinados à precisão e ao rigor podem jogar tal jogo duplo, além do mais, em um espaço de múltiplos andares, durante seis horas!

O ator pode, ao contrário, se dissolver, desaparecer, se tornar imaterial, como em João Sem Nome, espetáculo de Robert Lepage. Evoluindo em um ambiente 3D, composto por gravuras antigas em preto e em branco tratadas por computador, ele "se volatiliza". Às vezes, torna-se imaterial e transparente pela técnica que o apaga aos olhos do público ou impede o reconhecimento exato do lugar onde ele se encontra ou atua.

Na medida em que todo objeto presente sobre o palco modifica o espaço e o tempo cênico, o ator deve saber representar com esses novos objetos e acessórios ou instrumentos de representação que são as câmeras e as imagens, os microfones e os sons, que podem acentuar o realismo, ou levar à ilusão, destacar o objetivo, ou mergulhar no subjetivo. Caso particular, aquele dos textos que aparecem cada vez mais freqüentemente em cena: letreiros de tradução simultânea. Raros são aqueles que sabem utilizá-los ou que têm somente idéia de como fazer, e não é um acaso se os atores bem formados do Théâtre de Complicité ou aqueles do grupo do Volksbühne sabem se apropriar em sua atuação das legendas (Mnemonic). Como atuar com esse texto-tradução que acompanha as turnês de um espetáculo ao estrangeiro, mas, também, como atuar com um texto que pode ser projetado - as páginas de um livro servindo de dispositivo - sem parecer estar fazendo uma ilustração? E como atuar com sapatos recheados de microfones (sapatos MIDI) até então reservados aos bailarinos?

Em todas essas situações, o ator é colocado diante de problemas a resolver urgentemente. Ele deve saber como manter-se ao centro, como lugar principal da comunicação dramática com o espectador. A parceria desenvolvida pelos atores com os outros participantes do espetáculo, em geral, invisíveis quando da representação, se mostra, entretanto, agora, diferente, pois esses outros parceiros estão freqüentemente sobre a cena e ocupam um lugar cada vez mais importante - sejam os músicos que abandonaram o fosso ou as coxias ou os numerosos técnicos que, com seus materiais cada vez mais impressionam, se encontram sobre a cena, na sala, ou mesmo determinando com suas máquinas o espaço de representação do ator. Da mesma maneira como fizeram parte da produção durante os ensaios do espetáculo, eles permanecem co-presentes, interagindo com o público durante a representação. Novos modos de criação e de apresentação, em que se expõe aquilo que anteriormente pertencia à "cozinha", estão agora postos em jogo, exigindo tanto uma atuação muito precisa no trabalho quanto uma abertura à variação no tempo.

A técnica se torna um parceiro visível do ator ( $O$ Mundo de Hyc de Christophe Huysmans). Às vezes, é o próprio encenador quem filma os atores de seu espetáculo. Assim, em Caldéron de P.P. Pasolini ${ }^{17}$, inspirado de $A$ vida é um sonho, cujos temas envolvem um jogo com o irreal, Jean-Marc Musial é constantemente presente sobre a cena de forma a enquadrar e capturar de mais próximo as imagens dos atores, que igualmente são tomadas por 


\title{
OS NOVOS DESAFIOS DA IMAGEM E DO SOM PARA O ATOR: EM DIREÇÃO A UM "SUPER-ATOR"?
}

\author{
BÉATRICE PICON-VALLIN
}

outra câmera e difundidas pela cabine técnica, retratando-os ao vivo e os combinando com películas pré-registradas, incrustações e diferentes efeitos especiais, sobre telas em painel e monitores que compõem o dispositivo cênico. É a filmagem e seus desafios que fazem nascer o jogo teatral, preciso, justo e codificado para entrar no quadro. Longe de se sentir despossuído de sua imagem, o ator, consciente das múltiplas interações que se estabelecem a fim de que o espetáculo aconteça, compreende a forma, pensa-a e sabe se colocar e orientar seu olhar, oferecendo ao enquadramento do encenador o rigor e a intensidade controlada de sua atuação, por ele considerada como execução de uma partitura composta de seqüências curtas, elaboradas em função dos diversos suportes tecnológicos empregados. O grupo contempla tanto técnicos quanto atores. $\mathrm{O}$ encenador pode indicar inflexões balançando sua câmera como faz Naim June Park, invertendo a imagem, ou a deformando através de uma grande aproximação, desafiadora aos atores. Esses dialogam entre eles através de suas imagens e daquelas que foram produzidas durante a concepção do espetáculo. Enfim, seus microfones são religados a um sintetizador $\mathrm{O} 3 \mathrm{D}$, que duplica suas vozes, como se dois seres falassem dentro deles, mas que é considerado pelos atores como instrumento de música: modulam sua emissão vocal, jogam com ela antes que intervenha a modificação realizada pela técnica. A dualidade do ator não existe somente nele, ela está também fora dele: duplo visual, duplo vocal.

Piscator dizia, ao final dos anos cinqüenta: "A técnica no teatro tem a reputação de ser um mal necessário que entrava o exercício de uma arte muito mais do que somente a favorece". O ator dispõe, ao contrário, graças a ela, de novos acessórios com o que trabalha. As imagens e os sons ou as máquinas produtoras de imagens e sons constituem-se em prolongamentos de seu corpo, se integradas a sua atuação, em sua partitura de trabalho: são "ferramentas de movimento humano", assim como os bastões de Oskar Schelemmer nos anos vinte. Multiplicado, fragmentado, visto em todos os lugares, jogando com as imagens - na imagem, com parceiros-imagens, com as imagens-atrizes-, ele se encontra, então, confrontado à tarefa de ampliar os recursos expressivos de seu próprio corpo, de jogar diferentemente com o espectador e de estabelecer novas relações com os membros do coletivo de criação, alargado de videastas, de infografistas, etc.

O teatro era para Vitez, que remetia a Meyerhold, um "laboratório de condutas humanas"18. Atualmente, a cena é este lugar único onde estão postos o espectador e o ator diante de múltiplas imagens-representações que os circundam na vida quotidiana, de toda palheta de seus duplos tecnológicos, fotográficos, fílmicos, videográficos, clones virtuais ou marionetes eletrônicas. Ela é, sem dúvida, hoje, um dos raros espaços, ao mesmo tempo, experimentais e lúdicos onde se pensa as mutações tecnológicas em presença dos corpos vivos, aqueles dos atores e dos espectadores. Ela fomenta interrogações sobre o conceito de presença e sobre a maneira de criá-la, modificá-la, intensificá-la, pois a imagem ao vivo ou pré-gravada de um ator é freqüentemente mais fascinante do que o ator sobre a cena, porque é infinitamente modificável e móvel. A imagem do ator, cuja presença real sobre a cena não se 
tem certeza, sua "presença-ausente", suscita sempre uma interrogação extremamente forte por parte do espectador. $\mathrm{O}$ ator pode, então, tomar consciência, em tal laboratório teatral, dos diferentes registros de presença que estão a sua disposição e sobre os quais ele terá de organizar a partitura. Interiormente penetrado pela dualidade do ato teatral, ele está agora concretamente colocado diante de seu(s) duplo(s). As técnicas do som e da imagem podem auxiliar o ator a atuar à distância, despertando, todavia, no público o sentimento de intimidade, de proximidade. Elas podem, ainda, desviar a atenção do público para longe do corpo a partir de onde essas imagens e esses sons emanam. É deste paradoxo da presença e de suas aventurosas modalidades, mesmo fantásticas, que é preciso fazer um novo capítulo da história da formação do ator, no contexto de uma linguagem cênica que se torna muito mais complexa e de uma nova cultura do sensível: um capítulo que mestres e alunos desenvolvam em conjunto a uma proposta experimental, que, aliás, sempre foi aquela dos grandes pedagogos do teatro. 


\section{NOTAS:}

${ }^{1}$ Este artigo foi originalmente publicado In: Etudes Théâtrales, n. 26, Université deCatholique de Louvain Centre d'Études théâtrales, Louvain-la-Neuve, 2003.

${ }^{2}$ Professora do PPG Artes Cênicas/UFRGS. Essa tradução se faz no quadro de atividades do projeto de pesquisa "Homens e Fantasmas sobre a cena contemporânea", desenvolvida com apoio do CNPq.

${ }^{3}$ Peter Sellars, texto sobre a quarta capa. In: Paul Schmidt. Meyerhold at work. New York and London: Applause, nouvelle edition, 1996, trad. Fréderirc Maurin.

4 "Les gloses du Docteur Dapertutto" in Ljibov k trëm apel'sinam, Petersbourg, n. 4-5, 1914, p. 75.

${ }^{5}$ Béatrice Picon-Vallin. L'acteur poete. Théâtre/Public, Gennevilliers, n. 164, pp. 14-26, março-abril 2002.

${ }^{6}$ Écrits sur le theatre (1936-1940), v. 4. Lausanne: L'Age d'Homme, coll. "Th20", 1992, p. 346.

${ }^{7}$ Apud Stefan Priacel. Meyerhold à Paris. Paris, Le Monde, 07/07/1928. Essa entrevista reaparece, palavra a palavra, em Paris Midi e La Presse.

${ }^{8}$ Erwin Piscator. La technique, nécessité artistique du théâtre moderne (1959). In: Denis Bablet e Jean-Jacquot (org). Le Lieu théâtral dans la société moderne. Paris: Éditions CNRS, 1969, p. 138-140.

${ }^{9}$ Idem. Le Théâtre Politique. Paris: L'Arche, 1962, 138.

${ }^{10}$ Afirmação capital que ele expressa claramente mais tarde, em 1959, no artigo já citado La technique, nécessité artistique du théâtre moderne.

${ }^{11}$ Erwin Piscator. Pour un jeu objetctif, World Theater - Le theater dans le monde, Revue de l'IIR, ParisBruxelles, v. XVIII, 1968, p. 5-6.

${ }^{12}$ La numérisation du son, Culture et recherches, Paris, Ministhère de la Culture, n. 91-92, p. 3.

${ }^{13}$ Sobre tais questões: Les écrans sur la scène (org. Béatrice Picon-Vallin). Lausanne: L'Âge d'Homme, 1998; Denis Bablet. Svoboda. Lausanne: La Cité, 1970; Jacques Polieri. Scénographie. Théâtre,cinema, télévision. Paris: Jean-Michel Place, 1963 (1990).

${ }^{14}$ No Centre d'Art et d'Essai de Mont-Saint-Aignan, 2002.

${ }^{15}$ Forsythe, révolution de príncipe. Colocações colhidas por Anne-Sophie Vergne. Revue Mouvement, n. 18, set-out, 2002, p. 59.

${ }^{16}$ Entrevista. Peter Sellars. Tudo em cena. Colocações colhidas por Karen Rudolph (trad. S. Day e J. Bidjocka). Beaux Arts Magazine, n. 165, fev. 1998, p. 40-48.

${ }_{17}$ A.T.T.I.L.A. (Action Théâtre Technologie Image Laboratoire Artistique), Lille. Esse espetáculo foi apresentado no evento "Villete Numérique" à Paris, em outubro de 2002.

${ }^{18}$ Antoine Vitez. Écrits sur le theater, V. Paris: P.O.L., 1998, p. 228. 